\section{Presidential Perspective}

A strong post-war spirit of idealism drove the creators of the IUGS, to bring national or regional earth science bodies under one international banner. Now, some 40 years later, most of the slightly more than one million geoscientists on earth are linked internationally one way or another. This most certainly holds for the roughly 250,000 geoscientists who are members of the 37 international organisations affiliated to IUGS, and many more are internationally connected by e-mail or other electronic means. Geological structures cut through national boundaries, which thus become irrelevant to geoscientists.

International cooperation was also the aim of the founding fathers of the International Geological Correlation Programme. This year we celebrate the 30th anniversary of IGCP, the most successful scientific programme ever run by UNESCO or IUGS. The truly international character of IGCP stands out clearly; with some 1500 colleagues from some 145 countries are involved in its 40 projects every year. Leadership of IGCP projects is still typically based in the most developed countries but two of the five new IGCP projects approved this year will be led by developing countries. UNESCO and IUGS together have set aside 265,000 US dollars for the projects in 2002. In reality, this sum is multiplied more than 100 times by other sponsors who are confident that such projects, once approved by the prestigious IGCP Scientific Board, are worthwhile investing in.

International cooperation has become a strong issue for many geoscientific organisations today. This is partly due to reduced funding options, and partly to the realization that it is very difficult to get diversified messages across to our target organisations, which generally demand very brief descriptions supported by large communities. Driven by this need, geological surveys in Europe, Latin America and South East Asia cooperate together in regional bodies. With the SE Asian Group (CCOP), IUGS signed a Memorandum of Understanding in December 2001, and more such cooperative agreements are foreseen for the near future. Among other geoscientific bodies, the European Union of Geosciences and the European Geophysical Society have decided to cooperate closely, and IUGS is preparing to merge with the International Geological Congress. As part of our Strategic Action Plan, IUGS has moved to significantly expand ties with our affiliated organisations. Closer cooperation is also planned

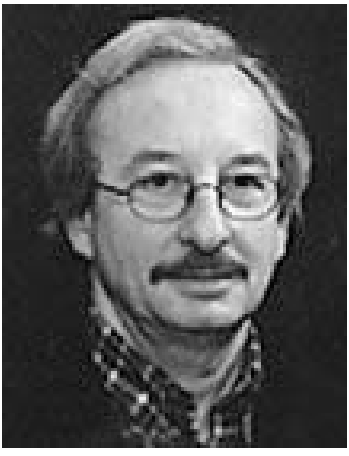
with our sister unions in the International Council of Science (ICSU), starting with the International Union of Geodesy and Geophysics (IUGG).

As the world becomes one big electronic village and scientists a closer-knit family, international cooperation should be given very high priority. This requires investing more in the participation of our colleagues in developing countries. They are now getting access, however limited, to the Internet, but they still lack funds for travel and for gaining access to international scientific literature. Scientists from developing countries who are involved in IGCP projects, however, already are linked into a major international scientific network. Therefore, the IGCP formula serves as an excellent example of how this may be achieved.

Eduardo F. J. de Mulder

President, International Union of Geological Sciences 13th April 2002 